Original article

\title{
Detrimental effect of temperature increase on the fitness of an amphibian (Lissotriton helveticus)
}

\author{
Valérie Galloy, Mathieu Denoël \\ Laboratory of Fish and Amphibian Ethology, Behavioural Biology Unit, University of Liège, \\ Quai van Beneden 22, 4020 Liège, Belgium
}

\begin{abstract}
Increases of global temperatures have resulted in measurable shifts in the distribution, phenology and survival of some plant and animal species. However, the mechanisms showing links between global warming and biodiversity declines remain unclear. The aim of this study was to examine whether a key parameter of fitness, i.e. offspring number, could be affected by a temperature increase. To this end, we compared egg-laying traits at naturally occurring temperatures $\left(14^{\circ} \mathrm{C}, 18^{\circ} \mathrm{C}\right.$ and $\left.22^{\circ} \mathrm{C}\right)$ in palmate newts, Lissotriton helveticus. Our study suggests that water temperature increase has a negative effect on the fecundity of female newts. Females lay half as many eggs at high temperatures as they do at low temperatures, which results in a lower number of hatchlings. This study shows that global warming would affect amphibian populations. It complements other studies in pointing out that changes in phenology may not be driven only by warmer earlier temperatures but also by counter-selection during late-breeding, particularly in long-term breeders such as newts. More experimental studies should be carried out to understand the complex consequences of global warming and the proximate mechanisms of amphibian decline.
\end{abstract}

2009 Elsevier Masson SAS. All rights reserved.

Keywords: Amphibian decline - Climate change - Fecundity - Global warming - Life-history trait Proximate causes

\section{Introduction}

Over the 20th century, the average global surface temperature has risen by about $0.6^{\circ} \mathrm{C}$. In addition, the 1990 s was the warmest decade since 1861 and data for the Northern Hemisphere indicate that the increase in temperature in the twentieth century is probably the largest during the past 1000 years (Jones et al., 2001; International Panel on Climate Change, 2002). A number of extreme events in weather and climate are predicted for the 21 st century. These include more hot days, higher minimum temperatures, fewer cold days, more intense precipitation events, and increased summer continental drying associated with drought (International Panel on Climate Change, 2002). Modelled projections for climate change in the next 100 years predict further accelerated levels of warming with a global temperatures expected to increase by $1.4-5.8 \mathrm{C}$ by the year 2100 (International Panel on Climate Change, 2002).

There is increasing evidence that a large number of species have been or would be affected by this rapid change of temperature (Thomas et al., 2004). At a spatial scale, shifts in abundance and distribution patterns have already been found in numerous plant and animal species (McCarty, 2001; Parmesan and Yohe, 2003; Root et al., 2003). At a temporal scale, long-term changes in phenology, including earlier flowering, emergence, migration and breeding have been documented (Walther et al., 2002; Parmesan and Yohe, 2003). For example, earlier spring shifts have been shown in birds (Crick et al., 1997), fishes (Gillet and Quétin, 2006) and amphibians (Beebee, 1995).

Environmental temperature changes are particularly expected to affect ectotherms because of their physiological and behavioural dependence on local temperature conditions (Rome et al., 1992). Above species-specific thresholds, temperature increase was shown to be detrimental to such organisms (Huey and Kingsolver, 1989; Angilletta et al., 2002). Temperature biases the sex ratio in reptiles causing disturbance in population structure (Janzen, 1994; Hawkes et al., 2007). In amphibians (common toads), it negatively affects the female body condition and survivorship (Reading, 2007), whereas the artificial suppression of hibernation advances sexual reproduction and possibly reduces fitness because of correlation between size and fecundity (Jørgensen, 1986). Despite this, the direct effects of temperature on fecundity are not clear as previous reports showed contrasting results. There was only one study on amphibians (Kaplan, 1987), which showed an increase of clutch size, with temperature, in an Asiatic toad after hormonal injection. In other organisms, such as invertebrates and fish, all patterns were found with highest fecundity at high (Ashamo and Odeyemi, 2004), low (Hotta et al., 2001; Brown et al., 2006; Reyjol et al., 2009) or intermediate (Collins and Leather, 2001; Pervez and Pervez, 2002) temperatures.

The present pdf is the author post-refereed pre-print. The post-refereed post-print (i.e., published pdf) is archived in an institutional repository (http://hdl.handle.net/2268/33153) and in the publisher website (http:// dx.doi.org/10.1016/j.actao.2009.12.002) (Elsevier) 
Amphibians are suitable models to test the effects of temperature increase because they are small ectotherms, from which fitness can be determined in the laboratory (Duellman and Trueb, 1994). The fact that they can live in a wide range of temperature is also interesting to test an effect of fecundity at temperatures that may be detrimental for reproduction, but not for activity. Amphibians are declining dramatically in many areas of the world and have done so particularly over the past 25 years (Houlahan et al., 2000; Lips et al., 2006). Climate change has been recognized as a proximate factor of extinction (Carey and Alexander, 2003; Collins and Storfer, 2003) and phenological change, such as earlier spring shifts (Beebee, 1995; Gibbs and Breisch, $2001)$. It is also believed to affect patterns of distribution of both localised and widespread species (Denoël et al., 2009; Popescu and Gibbs, 2009). Few studies have established causality between the climate change and the amphibian declines. They showed that a warmer climate, particularly mild winters, have consequences for body condition (Jørgensen, 1986; Reading, 2007) and larval development (Reading and Clarke, 1999), both of which have the potential to influence the dynamics of a population.

Our aim was to determine, experimentally, whether temperature increase could affect a key lifehistory trait, fecundity. Particularly, we hypothesize that fecundity may be altered at a high rearing temperature. To test this hypothesis, we compared in laboratory conditions egg-laying traits of palmate newts at naturally occurring temperatures, encompassing the predicting values under the forecasts of climate change.

\section{Materials and methods}

The study species, the palmate newt Lissotriton helveticus - previously named Triturus helveticus is common inWestern Europe and classed as "Least Concern" by the IUCN (Arntzen et al., 2008). This species breed in water, but uses also terrestrial habitat, particularly outside the breeding period (Denoël, 2007). A total of 240 adult palmate newts (120 males and 120 females) were caught by dipnetting in a cattle pond at La Plane, in SouthernLarzac, Department of Aveyron, France $\left(43^{\circ} 55^{\prime} 6^{\prime \prime} \mathrm{N}\right.$, $3^{\circ} 16^{\prime} 15^{\prime \prime} \mathrm{E}$, elevation $760 \mathrm{~m}$ a.s.l.). This study site is located in an area where the mean annual temperature $\left(10.6^{\circ} \mathrm{C}\right.$, WordClim: Hijmans et al., 2005) is predicted to have a $4^{\circ} \mathrm{C}$ increase by 2100 (International Panel on Climate Change, 2002). The pond is $75 \mathrm{~m}^{2}$ and $1.5 \mathrm{~m}$ deep. Water is clear and $\mathrm{pH}$, basic. Collection took place at the start of the breeding season in mid February 2007, just after the surface of the pond thawed. Months with average minimum temperatures below $0^{\circ} \mathrm{C}$ are December, January and February (WordClim data). Field and laboratory observations showed that palmate newts had not reproduced before sampling. After capture, the newts were carried directly to the laboratory by car in refrigerated and humid containers (no mortality during transportation).

Males and females were initially kept separately in six $800 \mathrm{~L}$ aquaria (40 individuals/aquarium). The newts were fed live Chironomus larvae ad libitum (60 mg/newt) every afternoon. Two aquaria were maintained at a mean temperature of $14.45^{\circ} \mathrm{C}$ (SE 0.07 ), two at $17.97^{\circ} \mathrm{C}$ (SE 0.08 ), and two at $21.92^{\circ} \mathrm{C}$ (SE 0.04). These three water temperatures were chosen because they were within the range of natural temperatures occurring during the reproductive activity of palmate newts at the study site. In the pond from where the newts were caught, we moni-

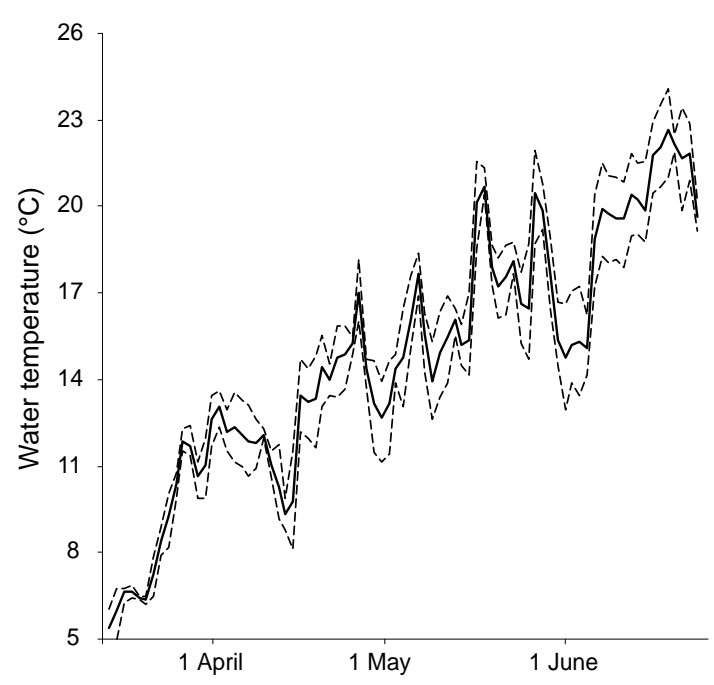

Fig. 1. Variations of water temperature during the courtship period of palmate newts: 14 March (Julian day 73 ) to 23 June 2006 (Julian day 174), La Plane, France. Solid line: mean temperature, dotted lines: minimum and maximum temperature.

tored temperature every day from the first to the last courtship act. Water temperature varied from $6.5^{\circ} \mathrm{C}$ to $23.5^{\circ} \mathrm{C}$ (mean $\pm \mathrm{SE}=14^{\circ} \mathrm{C} \pm 0.10$; Fig. 1$)$. Our maximum temperature $\left(22^{\circ} \mathrm{C}\right)$ is thus under the maximum temperature encountered by newts at the time of insemination. It is also fully realistic during egg-laying, which takes place during and after the courtship period, i.e. when temperatures reach higher values. In the laboratory, the photoperiod was set at $12.5 \mathrm{~L} / 11.5 \mathrm{D}$ to simulate the natural photoperiod. Each tank was oxygenated through airstones.

The newts were acclimated for 12 days in the laboratory prior to the onset of the experiments. After the experiment, all newts and resultant larvae were released to the site where the adults were originally collected.

Paired encounters $(n=120)$ were staged between 27 February and 21 March 2007. All encounters were unique, as each individual was used only once. In each experiment, one male and one female, both randomly chosen, were placed in an aquarium $(50 \mathrm{x}$ $25 \mathrm{~cm}$ and $30 \mathrm{~cm}$ high). The trials were conducted at three temperatures (mean $\pm \mathrm{SE}$ ): $13.91 \pm 0.03^{\circ} \mathrm{C}$ $(n=40) ; 18.11 \pm 0.04^{\circ} \mathrm{C}(n=40)$ and $21.94 \pm 0.04^{\circ} \mathrm{C}$ $(n=40)$; i.e. the animals were placed in the observation aquarium at a temperature similar to that of the maintenance aquaria. The light intensity was 5000 lux at the bottom of the aquarium (one daylight neon tube Lumilux de lux $2350 \mathrm{~lm}$, L36W/12950 and one normal neon tube Sylvania Professional, 36W DECOR183). The tank water was replaced after each trial. All encounterswere staged in the morning between 8:00 and 12:00. At the end of the encounter, the body mass of females was measured to the nearest of $0.1 \mathrm{~g}$.

The first sixty females ( $n=20$ for each temperature), who picked up at least one spermatophore deposited by the male during the sexual encounter (in such cases, the sperm mass adheres to the cloaca of females), were individually housed in tanks $(30 \mathrm{x}$ $20 \mathrm{~cm}$ and $17 \mathrm{~cm}$ high, $n=60$ ) with a plastic tube as refuge. Strips of filter paper $(7 \mathrm{~cm}$ long) were provided as an egg-laying substrate. The water temperature in these tanks was the same as that in the 
maintenance tanks from which came the newts.

Eggs were collected and counted each afternoon. Eggs from the same female were stocked in tanks $(15 \times 12 \mathrm{~cm}$ and $5 \mathrm{~cm}$ high, $n=60)$ with the same water temperature as that in the egg-laying tanks $\left(14,18\right.$ or $\left.22^{\circ} \mathrm{C}\right)$. Egg collection took place from 28 February to 25 May 2007. Egg collection was stopped when all females had finished laying their eggs, i.e. 65 days after insemination.

The oviposition number (number of deposited eggs; O1 hereafter), the oviposition period (measured as the number of days between the sperm transfer day and the last egg-laying; O2), and the rate of oviposition (calculated as the ratio between the number of deposited eggs and the oviposition period; O3), were recorded for each female. Considering the oviposition period as the time from the first and last deposited eggs gave identical results to the above indicated index. To avoid redundancy, we have chosen to present only the first index. Variables associated with hatching were also recorded: the number of hatchlings (H1), the latency (the number of days between the first oviposition and the first egg to hatch; $\mathrm{H} 2$ ) and the hatching success (the total number of eggs hatching as a proportion of the total number of eggs laid; H3).

A multivariate analysis of variance (MANOVA) was used to determine the significance of water temperature on variables associated with oviposition and hatching. Subsequent ANOVAs were used

Oviposition
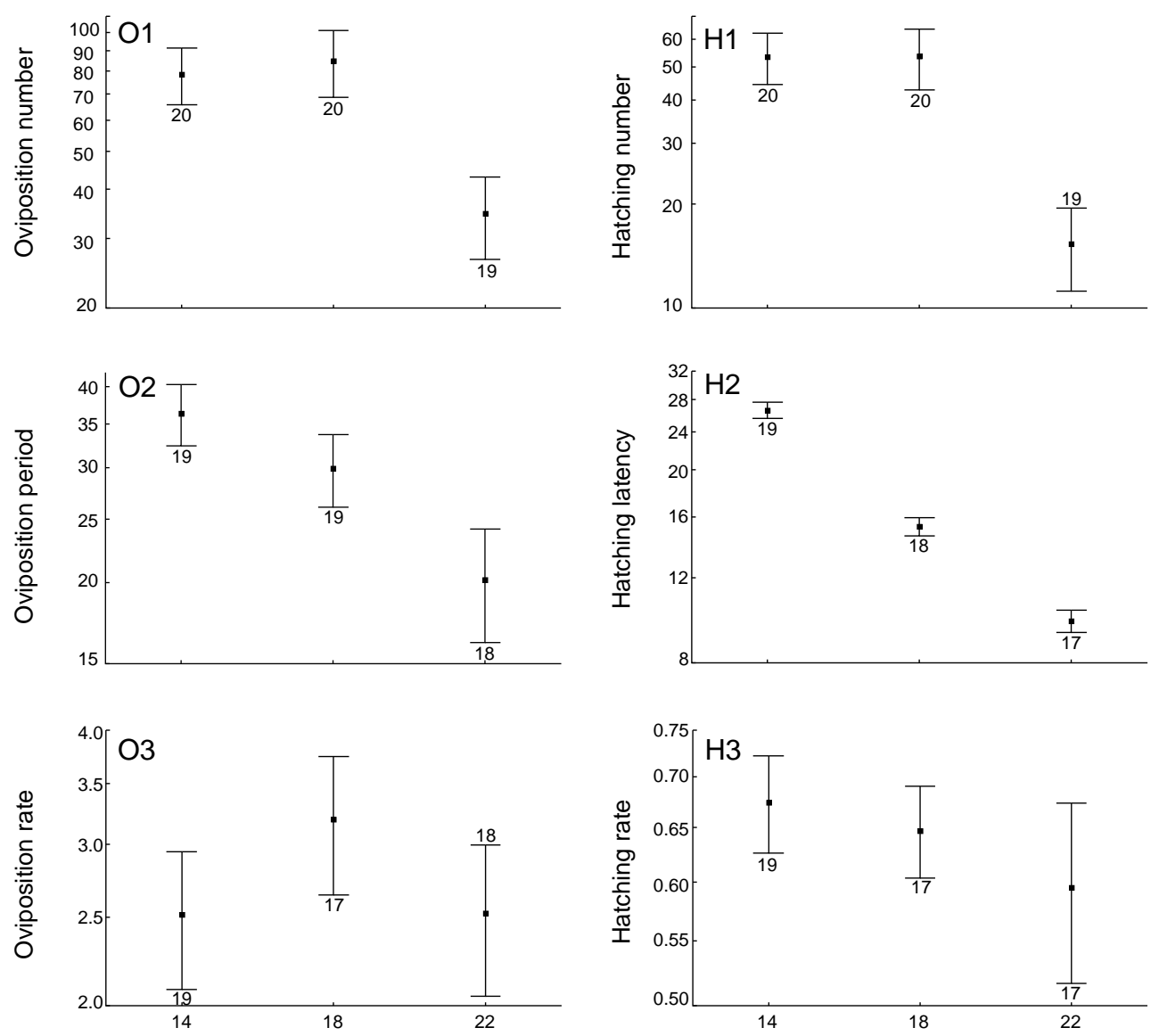

Treatment (water temperature ${ }^{\circ} \mathrm{C}$ )

Fig. 2. Effect of temperature treatment on the oviposition (left) and hatching (right) of palmate newts. O1: Oviposition number (number of laid eggs); O2: Oviposition period (from copulation to the last deposited eggs); O3: Oviposition rate (number of eggs deposited per day during the oviposition period); H1: Hatching number (number of eggs that hatched)H2: Hatching latency (time from oviposition to the first hatching); H3: Hatching rate (number of hatched eggs over the number of deposited eggs). See text for statistical results.

to determine the effect of temperature on the six life-history variables. When ANOVAs showed signiments were compared using Bonferroni's post-hoc corisons to take into account the experimentwise error. All variables were normalized by arcsquare-root (counts) transformation before calculating the parametric significance test (Sokal and eresented graphically. Statistic were carried out using Statistica 7.1. The signifi-

All but one female in each temperature group oviposited during the $65-\mathrm{d}$ experiment $(n=59)$. Females body mass among the three water treatments (mean $=2.3 \mathrm{~g} \pm 0.1 ;$ ANOVA: $\left.F_{256}=0.005, P=0.99\right)$ $0.662, F_{698}=3.737 ; P$ $F_{2.53}=4.561, P<0.05$; Fig. $\left.2-\mathrm{O} 1\right)$ : half as many eggs were laid at the highest temperature than at either of the two lower temperatures (Bonferroni's test: $P$

\section{Hatching}


$<0.05)$. The longest oviposition period was at the lowest temperature (ANOVA: $F_{2.53}=5.646, P<0.01$; Bonferroni's test: $P<0.01$; Fig. $2-\mathrm{O} 2)$. There was no significant difference among treatments in the rate of oviposition (ANOVA: $F_{2,51}=0.461, P=0.63$; Fig. 2-O3).

Hatching was also affected by temperature (MANOVA: Wilk's $\left.\lambda=0.129, F_{6,96}=28.622, P<0.001\right)$. The number of hatchlings was three times larger at the two lowest temperatures than at the highest (ANOVA: $F_{2,51}=7.763, P<0.01$; Bonferroni's test: $P<0.01$; Fig. $2-\mathrm{H} 1)$. Eggs hatched significantly later at low temperature: 11 days later at $14^{\circ} \mathrm{C}$ than at $18^{\circ} \mathrm{C}$ and 17 days later than at $22^{\circ} \mathrm{C}$ (ANOVA: $F$ $=109.381, P<0.001$; Bonferroni's test: $P<0.001$; Fig. 2-H2). Hatching rate, i.e. the proportion of the eggs that hatched, was not significantly dependent on temperature (ANOVA: $F_{2,50}=0.388, P=0.68$; Fig. 2-H3).

\section{Discussion}

This study showed that water temperature has an effect on the fecundity of palmate newts. An increase of water temperature experienced by palmate newts during the natural breeding period had a clear negative effect as only half as many eggs were laid at the highest temperature compared with the two lower temperature treatments, which results in only a third of hatchlings. Our experimental results provide clear evidence that temperature increase has a direct detrimental effect on a reproductive output in an amphibian, which might, particularly in threatened species, results in their decline. Previous studies on global warming focused mainly on phenological change and survival (McCarty, 2001; Walther et al., 2002; Parmesan and Yohe, 2003; Root et al., 2003). Those on amphibians showed earlier breeding (Reading, 1998), behavioural tolerance (Denoël, 1998; Denoël et al., 2005), population crashes during hot summers (Denoël, 2006), and reduced fecundity in mild winters due to smaller body size (Reading, 2007). The present results extend their support in proposing an additional possible explanation to declines but also to changes in phenology. They are also similar to those recently obtained in the bullhead, a fish species, for which the relative mass allocation to gonads decreased as temperature increased (Reyjol et al., 2009).

Low egg and larval production means a reduction of the reproductive rate of the species. In nature, egg survival is twenty times lower than in the laboratory (Miaud, 1991): 3\% against $64 \%$ in our experiments. If fecundity is reduced by one half to one third in a natural situation, this would lead to a very low hatching success, with, consequently, possibly longterm population consequences. However, population-level responses (e.g. population growth rate) are harder to predict (Biek et al., 2002), especially because density dependence may buffer against such negative impacts (Vonesh and De la Cruz, 2002). Further studies are clearly needed to test whether the effects of factors extrinsic to the population on larvae or adults translate into effects on population growth and ultimately population declines (Vonesh and De la Cruz, 2002).

Although field studies on reptiles (ChamailléJammes et al., 2006) found that global warming was associated with an increase of body size, and thus of clutch size, the potential benefit for palmate newts could not balance the important drawback. Although a strategy could be to produce fewer but bigger eggs, it was not the case in the present study where we found a lower hatching rate at the highest temperature but also larvae with shorter length at hatching, i.e. when fewer eggs were produced. Moreover, some larvae displayed deformities such as curved tails few days after hatching at $22^{\circ} \mathrm{C}$. This may be due to a too fast developmental rate at the highest temperature (the first eggs hatched three times faster at $22^{\circ} \mathrm{C}$ than as $\left.14^{\circ} \mathrm{C}\right)$. Voss $(1993)$ showed also, in Ambystoma maculatum, that at high temperatures, larvae emerge at smaller body sizes and less advanced developmental stages.

The underlying mechanisms explaining the decrease of female oviposition at high temperature are unknown. Gravid females had higher rates of oxygen consumption with increasing temperatures in comparison with postgravid females (Finkler, 2006). Egg-laying may also be costly due to greater energetic expenditure. It would be energetically advantageous for a female to resorb eggs or delay egg laying when environmental temperatures are not favourable for offspring's survival (Santolamazza-Carbone et al., 2008). On the other hand, because reproductive hormones, such as prolactine, are temperature-dependent in newts (Takahashi et al., 2001; Mosconi et al., 2002), it could be hypothesized that too high temperatures may cause changes in hormone concentrations, which in turns may influence egg production. Further investigations are needed to describe the physiological mechanisms mediating these effects.

\section{Conclusions}

Amphibians have been already widely advocated as good biological indicators of environmental health (Wake, 1991). The response of palmate newts to temperature increase could thus be viewed as alarming. Studies investigating a relationship between phenology of breeding and climate change have found contradictory results between amphibian species, some were breeding earlier and others were not (Gibbs and Breisch, 2001). Our results highlight that phenology would not change only because temperatures start to be warmer earlier (Beebee, 1995; Walther et al., 2002), but also because late-breeding would be counter-selected by high temperatures. As amphibians are essential parts of the trophic chain between aquatic and terrestrial ecosystems (Burton and Likens, 1975), their disappearance, or changes in phenology, may also have broader effects with changes in the structure of communities and ecosystem dynamics (Burton and Likens, 1975; Donnelly and Crump, 1998).

Despite the large interest on the consequences of climate change, little is known on the mechanisms by which species could decline. The main reason comes from the complexity of processes involving living organisms. On one hand, our study highlights a direct risk of high temperatures on fecundity, but on another hand it appeals for additional research to understand how changes in fecundity could translate into declines in the wild. It also shows that biological indicators such as amphibians are particularly recommended to assess environmental changes as they can be very sensitive to climatic alterations.

\section{Acknowledgements}

We are very grateful to W. Lo Presti for help in the field and laboratory, to Francesco Ficetola for extracting Worldclim data, and to C.J. Reading for his constructive comments on the manuscript. Collecting permit was delivered by the Prefecture of Aveyron, which allows the capture of palmate newts and 
the laboratory study (Arrêté 2006-02, 6 March 2006). The study was carried out in an agreed laboratory and approved by the ethical committee of the University of Liège. V. Galloy is a PhD student at the F.R.I.A. - Fonds pour la Formation à la Recherche dans l'Industrie et dans l'Agriculture. M. Denoël is a Research Associate at the F.R.S. - Fonds National de la Recherche scientifique. This research benefited from grants F.R.S.

FNRS 1.5.1999.07, 1.5.013.08 and 1.5.010.09.

\section{References}

Angilletta, M.J.J., Niewiarowski, P.H., Navas, C.A., 2002. The evolution of thermal physiology in ectotherms. J. Therm. Biol. 27, 249-268.

Arntzen, J.W., Beebee, T., Jehle, M., Denoël, M., Schmidt, B., Bosch, J., Miaud, C., Tejedo, M., Lizana, M., Martínez-Solano, I., Salvador, A., García-París, M., Gil, E.R., Sá-Sousa, P., Geniez, P., 2008. Lissotriton helveticus. In: IUCN 2009. IUCN Red List of Threatened Species. Version 2009.2 (www.iucnredlist.org).

Ashamo, M.O., Odeyemi, O.O., 2004. Effect of temperature on the development of the yam moth, Sasyses rugosella Stainton (Lepidoptera: Tineidae). J. Stor. Prod. Res. 40, 95-102.

Beebee, T.J.C., 1995. Amphibian breeding and climate change. Nature 374, 219-220.

Biek, R., Funk, W.C., Maxell, B.A., Mills, L.C., 2002. What is missing in amphibian decline research: insights from ecological sensitivity analysis. Conserv. Biol. 16, 728-734.

Brown, P., Shilds, R.J., Bromage, R., 2006. The influence of water temperature on spawning patterns and egg quality in the Atlantic halibut (Hippoglossus hippoglossus L.). Aquaculture 261, 993-1002.

Burton, T.M., Likens, G.E., 1975. Energy flow and nutrient cycling in salamander populations in the Hubbard Brook experimental forest, New Hampshire. Ecology 56, 1068 1080.

Carey, C., Alexander, M.A., 2003. Climate change and amphibian declines: is there a link? Divers. Distrib. 9, 111-121.

Chamaillé-Jammes, S., Massot, M., Aragon, P., Clobert, J., 2006. Global warming and positive fitness response in mountain populations of common lizards Lacerta vivipara. Glob. Change Biol. 12, 392-402.

Collins, C.M., Leather, S.R., 2001. Effect of temperature on fecundity and development of the Giant Willow Amphid, Tuberolachnus salignus (Sternorrhynca: Aphididae). Eur. J. Entomol. 98, 177-182.

Collins, J.P., Storfer, A., 2003. Global amphibian declines: sorting the hypotheses. Divers. Distrib. 9, 89-98.

Crick, H.Q.P., Dudley, C., Glue, D.E., Thomson, D.L., 1997. UK birds are laying eggs earlier. Nature 388, 526.

Denoël, M., 1998. The modulation of movement as a behavioral adaptation to extreme environments in the newt Triturus alpestris cyreni. J. Herpetol. 32, 623-625.

Denoël, M., 2006. Seasonal variation of morph ratio in facultatively paedomorphic populations of the palmate newt Triturus helveticus. Acta Oecol. 29, 165-170.

Denoël, M., 2007. Le Triton palmé, Triturus helveticus (Razoumowski, 1789). In: Jacob, J.P., Percsy, C., DeWavrin, H., Graitson, E., Kinet, T., Denoël, M., Paquay, M., Percsy, N., Remacle, A. (Eds.), Amphibiens et Reptiles de Wallonie. Aves-Raînne \& Région wallonne, Namur, pp. 86-95.

Denoël, M., Ficetola, G.F., Cirovic, R., Radovic, D., Dzukic, G., Kalezic, M.L., Vukov, T.D., 2009. A multi-scale approach to facultative padomorphosis of European newts in the Montenegrin karst: distribution pattern, environmental variables and conservation. Biol. Conserv. 142, 509-517.

Denoël, M., Mathieu, M., Poncin, P., 2005. Effect of water temperature on the courtship behavior of the Alpine newt Triturus alpestris. Behav. Ecol. Sociobiol. 58, 121-127.

Donnelly, M.A., Crump, M.L., 1998. Potential effects of climate change on two neotropical amphibian assemblages. Clim. Change 39, 541-561.

Duellman, W.E., Trueb, L., 1994. Biology of Amphibians. John Hopkins Univ. Press, Maryland.

Finkler, M.S., 2006. Effects of temperature, sex, and gravidity on the metabolism of small-mouthed salamanders, Ambys- toma texanum, during the reproductive season. J. Herpetol. $40,103-106$.

Gibbs, J.P., Breisch, A.R., 2001. Climate warming and calling phenology of frogs near Ithaca, New York, 1900-1999. Conserv. Biol. 15, 1175-1178.

Gillet, C., Quétin, P., 2006. Effect of temperature changes on the reproductive cycle of roach in Lake Geneva from 1983 to 2001. J. Fish Biol. 69, 518-534.

Hawkes, L.A., Broderick, A.C., Godfrey, M.H., Godley, B.J., 2007. Investigating the potential impacts of climate change on a marine turtle population. Glob. Change Biol. $13,1-10$.

Hijmans, R.J., Cameron, S.E., Parra, J.L., Jones, P.G., Jarvis, A., 2005. Very high resolution interpolated climate surfaces for global land areas. Int. J. Clim. 25, 1965-1978.

Hotta, K., Tamura, M., Watanabe, T., Nakamura, Y., Adachi, S., Yamauchi, K., 2001. Changes in spawing characteristics of Japanese whiting Sillago japonica under control of temperature. Fish. Sci. 67, 1111-1118.

Houlahan, J.E., Findlay, C.S., Schmidt, B.R., Meyer, A.H., Kuzmin, S.L., 2000. Quantitative evidence for global amphibian population declines. Nature 404, 752-755.

Huey, R.B., Kingsolver, J.G., 1989. Evolution of thermal sensitivity of ectotherm performance. Trends Ecol. Evol. 4, 131-135. International-Panel-on-Climate-Change, 2002. Climate Change and Biodiversity.

IPCC Technical Paper V. WMO, UNEP.

Janzen, F.J., 1994. Climate change and temperature-dependent sex determination in reptiles. Proc. Natl. Acad. Sci. U.S.A. 91, 7487-7490.

Jones, P.D., Osborn, T.J., Briffa, K.R., 2001. The evolution of climate over the last millenium. Science 292, 662-666.

Jørgensen, C.B., 1986. External and internal control of patterns of feeding, growth and gonadal function in a temperate zone anuran, the toad Bufo Bufo. J. Zool. 210, 211-241.

Kaplan, R.H., 1987. Developmental plasticity and maternal effects of reproductive characteristics in the frog, Bombina orientalis. Oecologia 71, 273-279.

Lips, K.R., Brem, F., Brenes, R., Reeve, J.D., Alford, R.A., Voyles, J., Carey, C., Livo, L., Pessier, A.P., Collins, J.P., 2006. Emerging infectious disease and the loss of biodiversity in a Neotropical amphibian community. Proc. Natl. Acad. Sci. U.S.A. 103, 3165-3170.

McCarty, J.P., 2001. Ecological consequences of recent climate change. Conserv. Biol. 15, 320-331.

Miaud, C., 1991. Essai de synthèse sur les caractéristiques démographiques des tritons du genre Triturus. Bull. Soc. Herp. Fr. 59, 1-18.

Mosconi, G., Cardinali, M., Yamamoto, K., Kikuyama, S., Vellano, C., Polzonetti-Magni, A.M., 2002. Temperaturedependent prolactin secretion and reproductive biology of the newt Triturus carnifex Laur. Gen. Comp. Endocrinol. 126, 261-268.

Parmesan, C., Yohe, G., 2003. A globally coherent fingerprint of climate change impacts across natural systems. Nature 421, 37-42.

Pervez, O., Pervez, A., 2002. Influence of temperature on age-specific fecundity of the ladybeetle Micraspis discolor (Fabricius). Ins. Sci. Appl. 22, 61-65.

Popescu, V.D., Gibbs, J.P., 2009. Interactions between climate, beaver activity, and pond occupancy by the coldadapted mink frog in New York State, USA. Biol. Conserv. 142, 2059-2068.

Reading, C.J., 1998. The effect of winter temperatures on the timing of breeding activity in the common toad Bufo bufo. Oecologia 117, 469-475.

Reading, C.J., 2007. Linking global warming to amphibian declines through its effects on female body condition and survivorship. Oecologia 151, 125-131.

Reading, C.J., Clarke, R.T., 1999. Impacts of climate and density on the duration of the tadpole stage of the common toad Bufo bufo. Oecologia 121, 310-315.

Reyjol, Y., Léna, J.-P., Hervant, F., Pont, D., 2009. Effects of temperature on biological and biochemical indicators of the life-history strategy of bullhead Cottus gobio. J. Fish Biol. 75, 1427-1445.

Rome, L.C., Stevens, E.D., John-Adler, H.B., 1992. The influence of temperature and thermal acclimation on physiological function. In: Feder, M.E., Burggren, W.W. (Eds.), Environmental Physiology of the Amphibians. The University of Chicago Press, Chicago, pp. 183-205. 
Root, T.L., Price, J.T., Hall, K.R., Schneider, S.H., Rosenzweig, C., Pounds, J.A., 2003. Fingerprints of global warming on wild animals and plants. Nature 421, 5760.

Santolamazza-Carbone, S., Nieto, M., Cordero, A., 2008. Egg resorption behaviour by the solitary egg parasitoid Anaphes nitens under natural conditions. Ent. Exp. Appl. 127, 191-198.

Sokal, R.R., Rohlf, F.J., 1995. Biometry. Freeman, New York.

Takahashi, N., Hasunuma, I., Iwata, T., Umezawa, K., Yamamoto, K., Marin, A., Perroteau, I., Vellano, C., Kikuyama, S., 2001. Molecular cloning of newt prolactin (PRL) cDNA: effect of temperature on PRL mRNA expression. Gen. Comp. Endocrinol. 121, 188-195.

Thomas, C.D., Cameron, A., Green, R.E., Bakkenes, M., Beaumont, L.J., Collingham, Y. C., Erasmus, B.F.N., Ferreira de Siqueira, M., Grainger, A., Hannah, L., Hughes, L., 2004. Extinction risk from climate change. Nature 427, $145-148$.

Vonesh, J.R., De la Cruz, O., 2002. Complex life cycles and density dependence: assessing the contribution of egg mortality to amphibian decline. Oecologia 133 , 325-333.

Voss, S.R., 1993. Effect of temperature on body-size, developmental stage, and timing of hatching in Ambystoma maculatum. J. Herpetol. 27, 329-333.

Wake, D.B., 1991. Declining amphibian populations. Science 253, 860 .

Walther, G.R., Post, E., Convey, P., Menzel, A., Parmesan, C., Beebee, T.J.C., Fromentin, J.-M., Hoegh-Guldberg, O., Bairlein, F., 2002. Ecological responses to recent climate change. Nature 416, 389-395. 